\title{
Highly Active Nanostructured Ni-Cu Electrocatalysts for the Oxygen Evolution Reaction
}

\section{$\mathbb{N}$}

Rajendra P. Gautam, Hanqing Pan, Farzaneh Chalyavi, Matthew J. Tucker, and Christopher J. Barile

Department of Chemistry, University of Nevada, Reno, NV , USA.

\section{Introduction}

Hydrogen can be produced in a clean and renewable manner from the electrolysis of water.

The efficiency of current water electrolyzer is limited by the slow kinetics of the oxygen evolution reaction (OER).

OER involves several povolion reaction (OER). ov to large reacton bariors and therefore require high overpotential to dive the reaclion in reasonable rates.

whased materials are promising electrocatalysts for the OER for water splitting in alkaline media.

Ni-Cu bimetallic compositions show superior OER performance in alkaline media. Ni-Cu nanostructured bimetallic compositions are one of the most efficient nonprecious metal OER electrocatalysts reported.

MALDI-TOF and ESI Mass Spectra

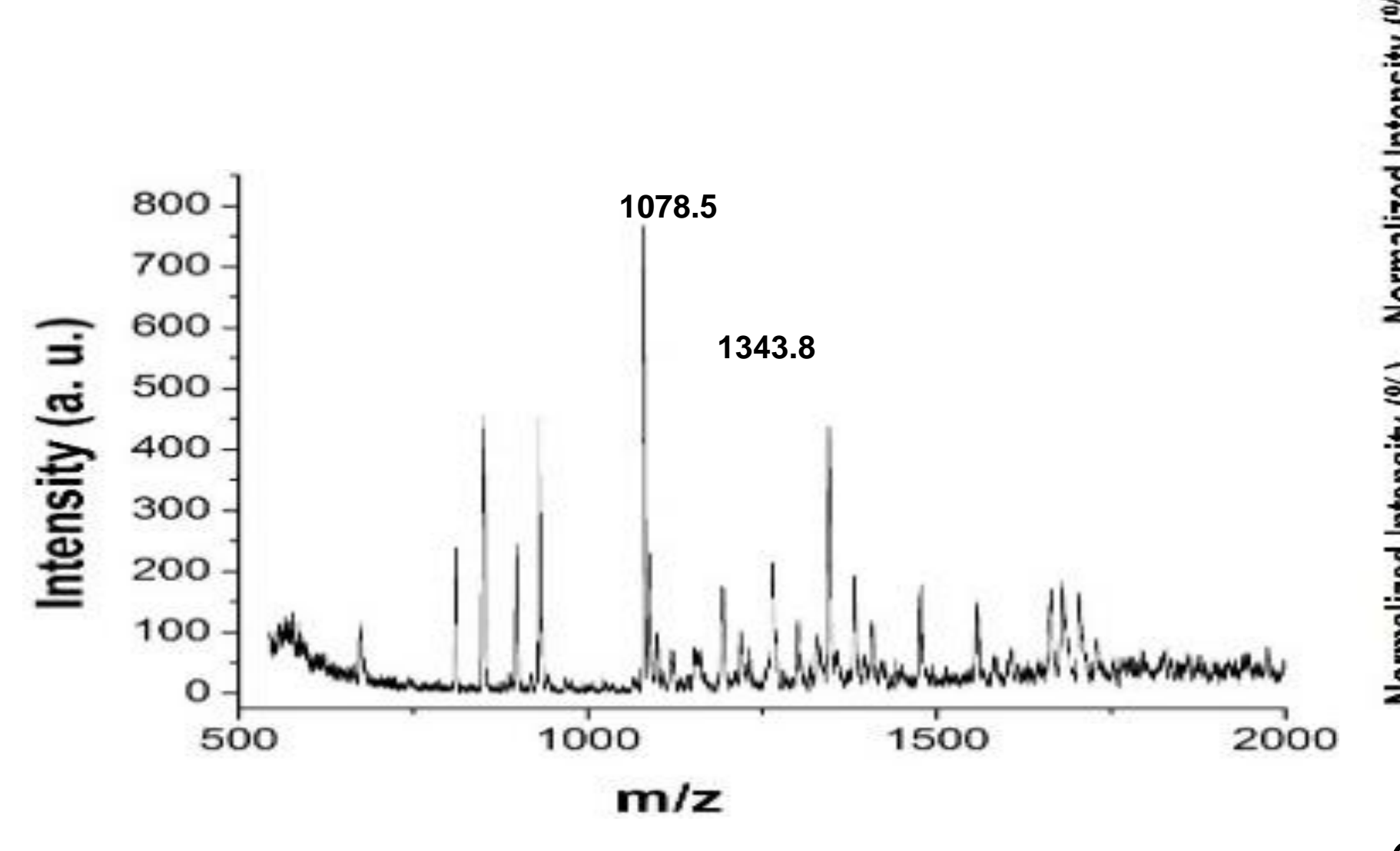

Positive-mode MALDI-TOF mass spectrum
of $52: 48$ mol\% Ni-Cu nanoclusters

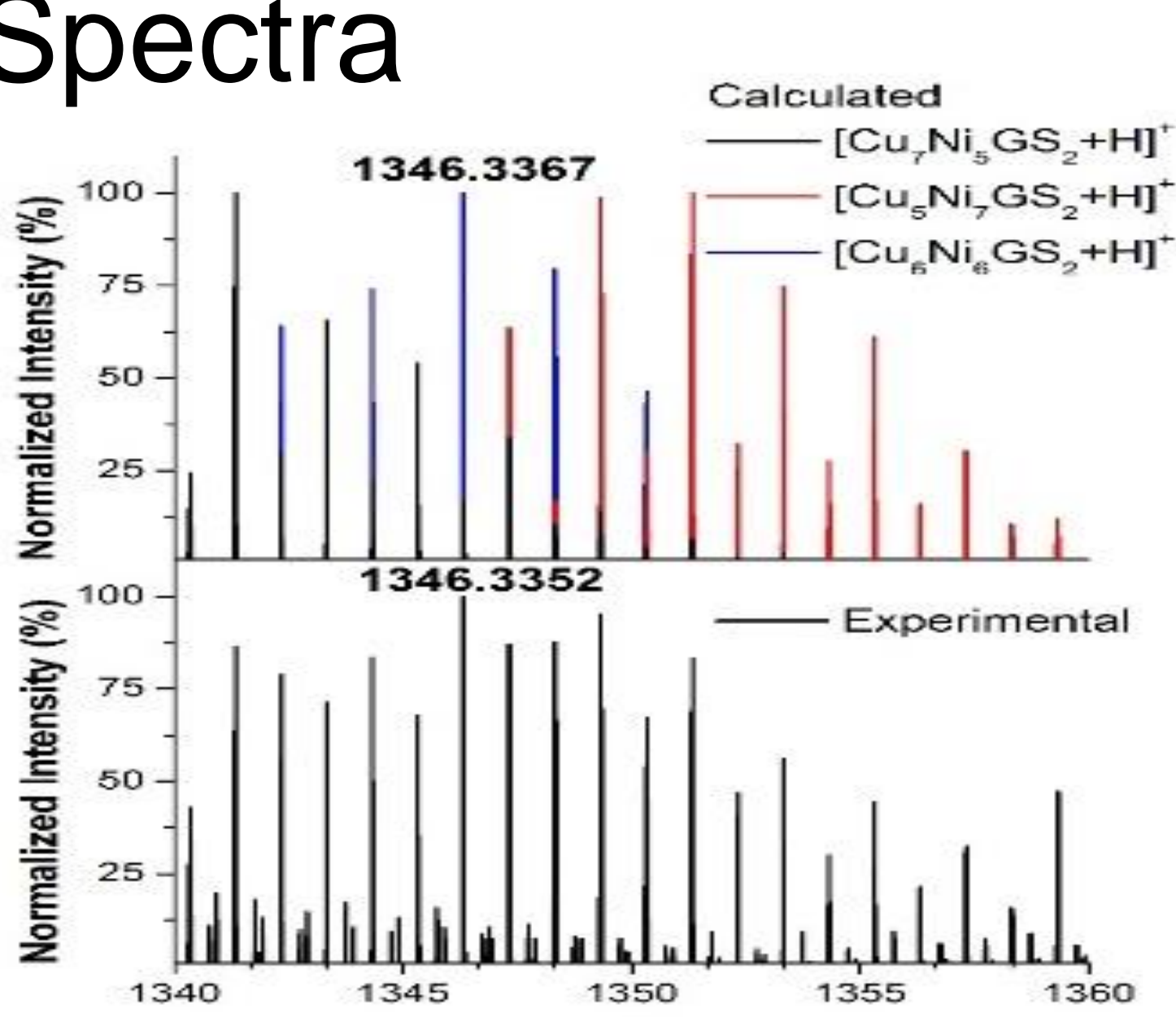

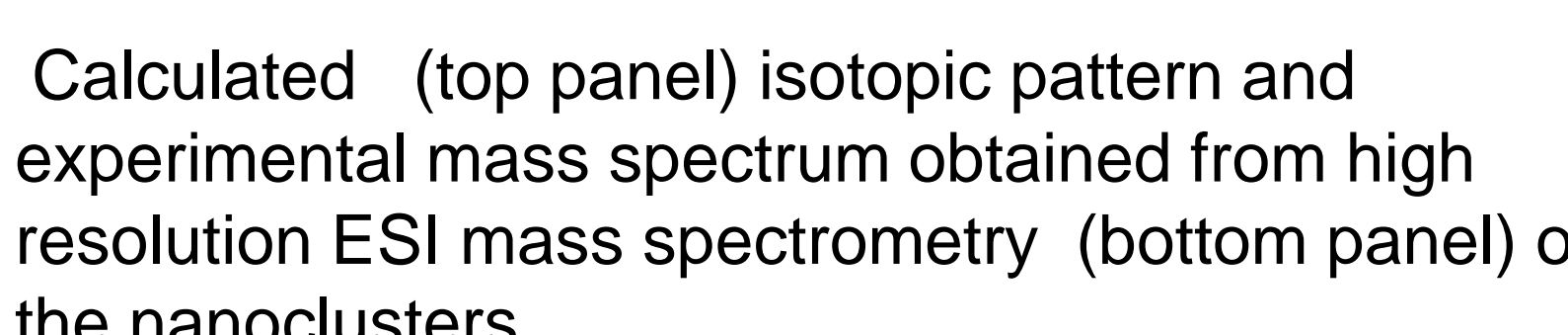

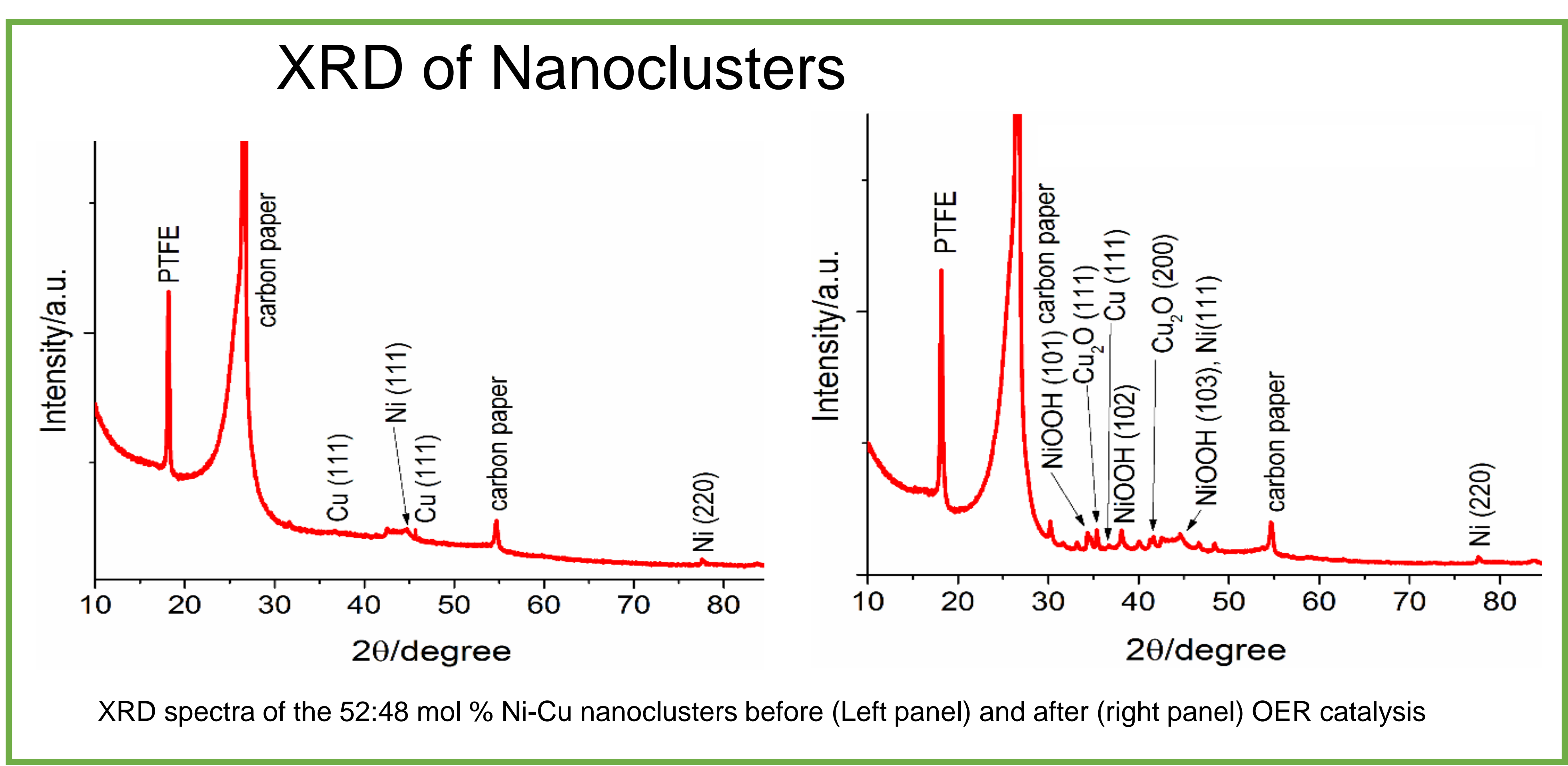

SEM Images and EDX Spectra

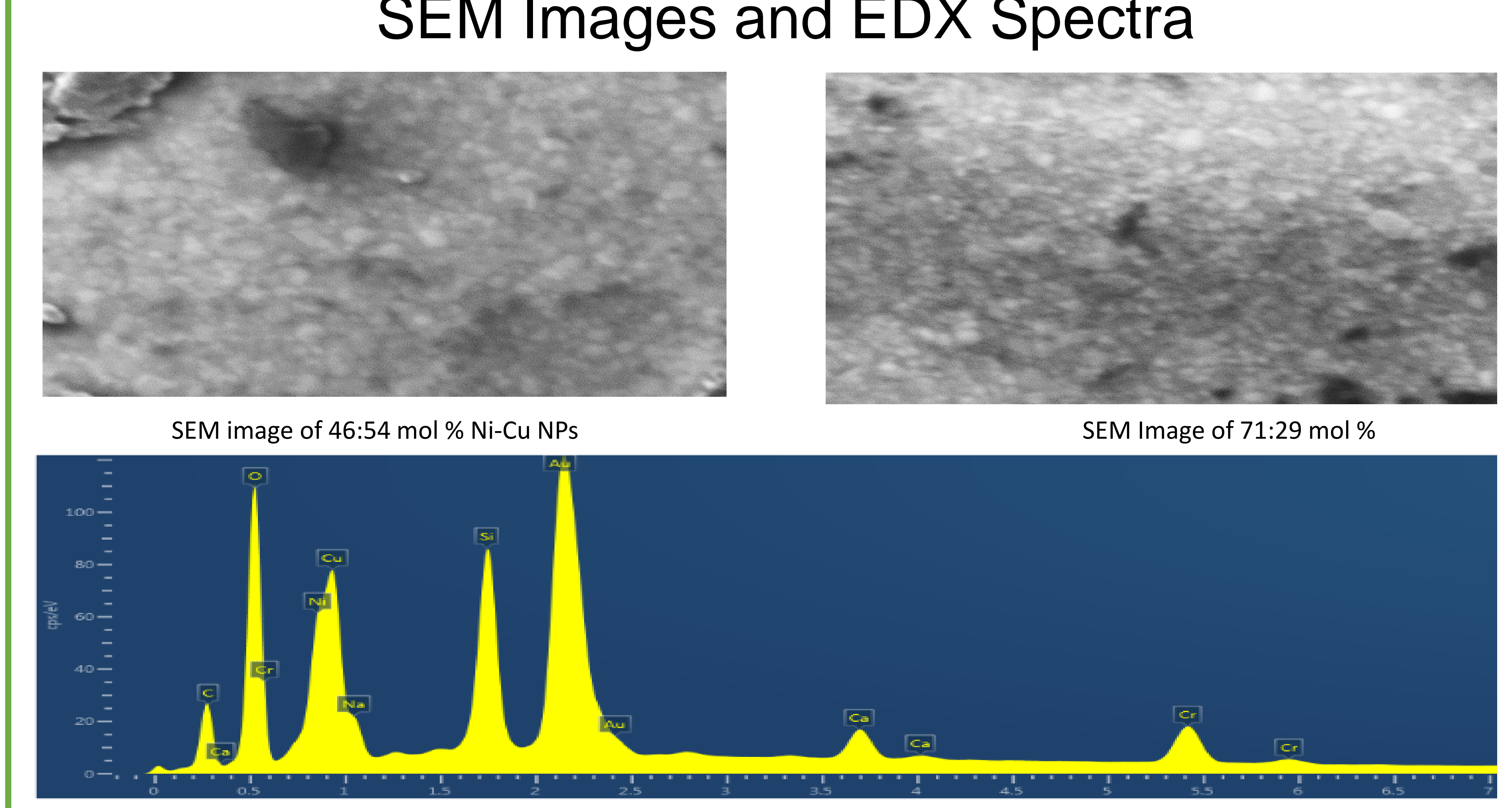

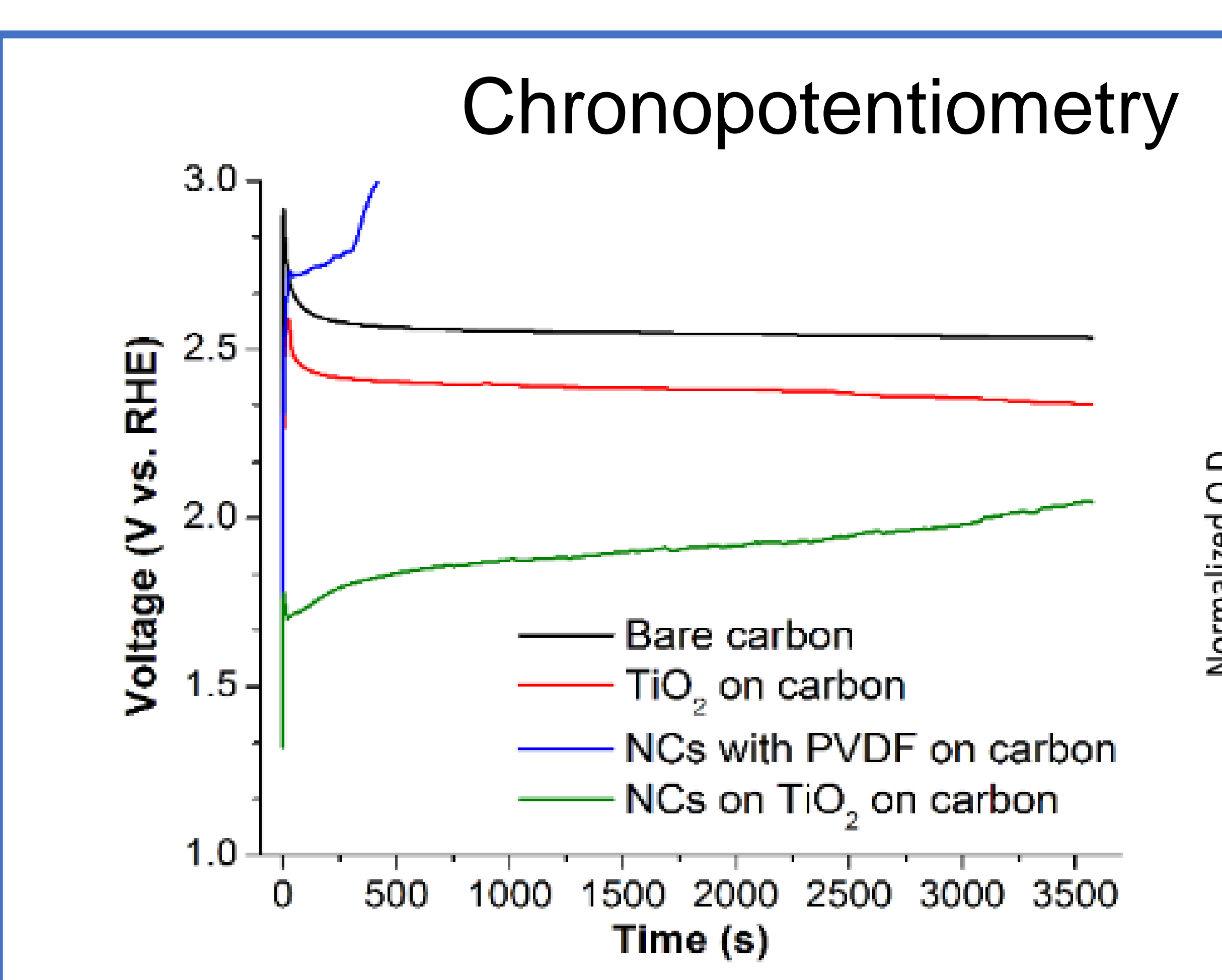

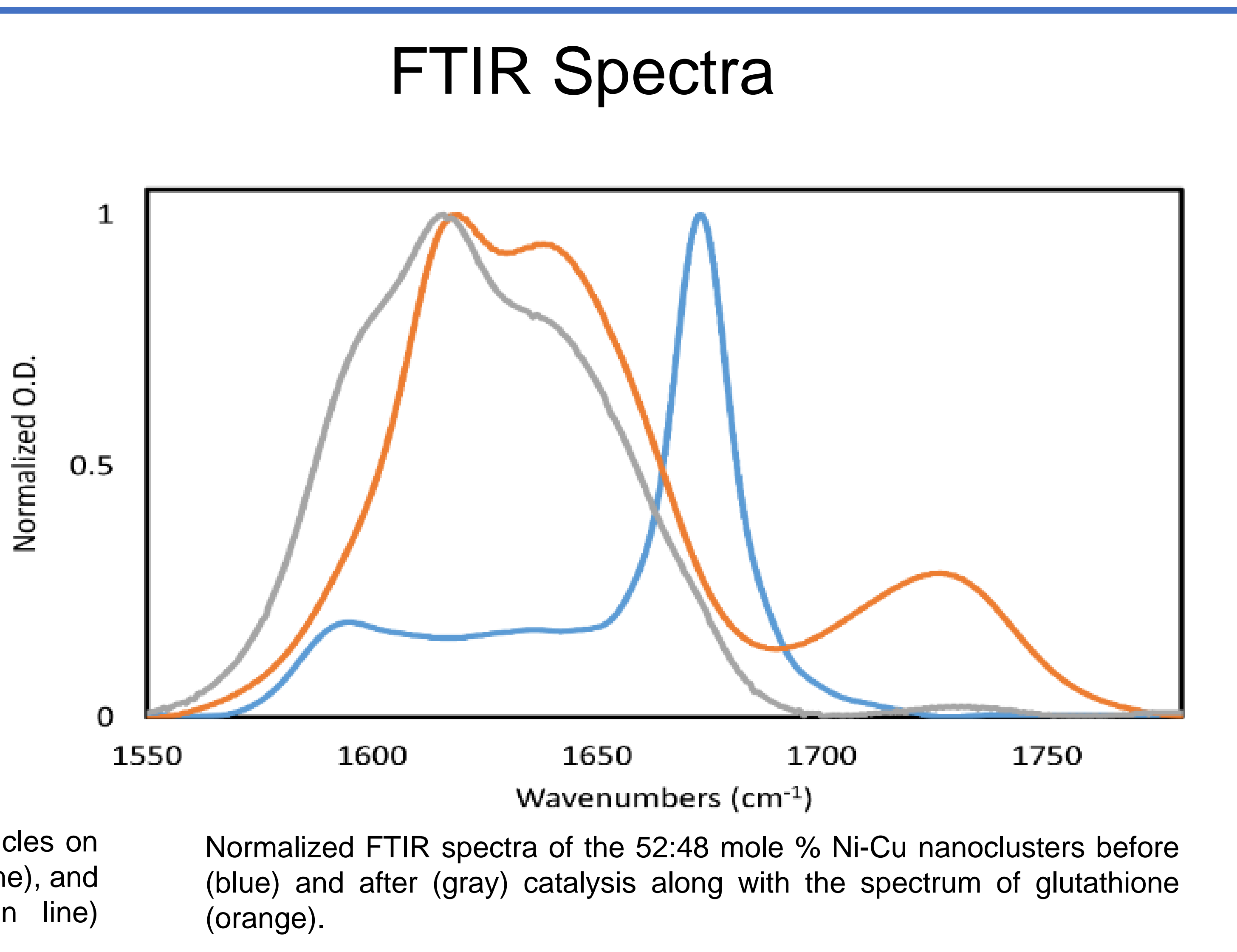

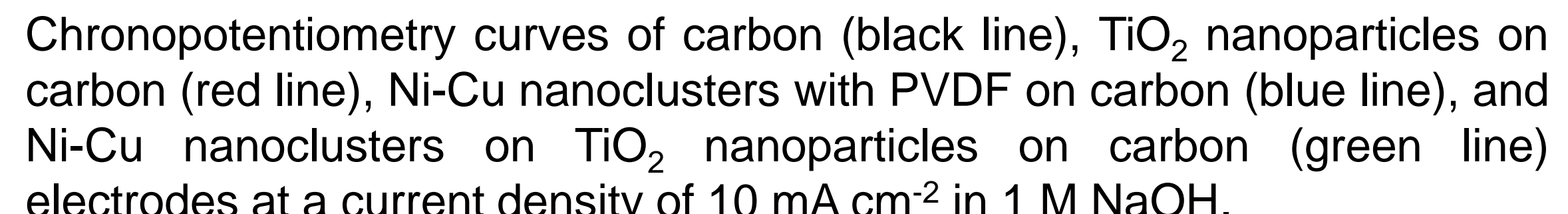
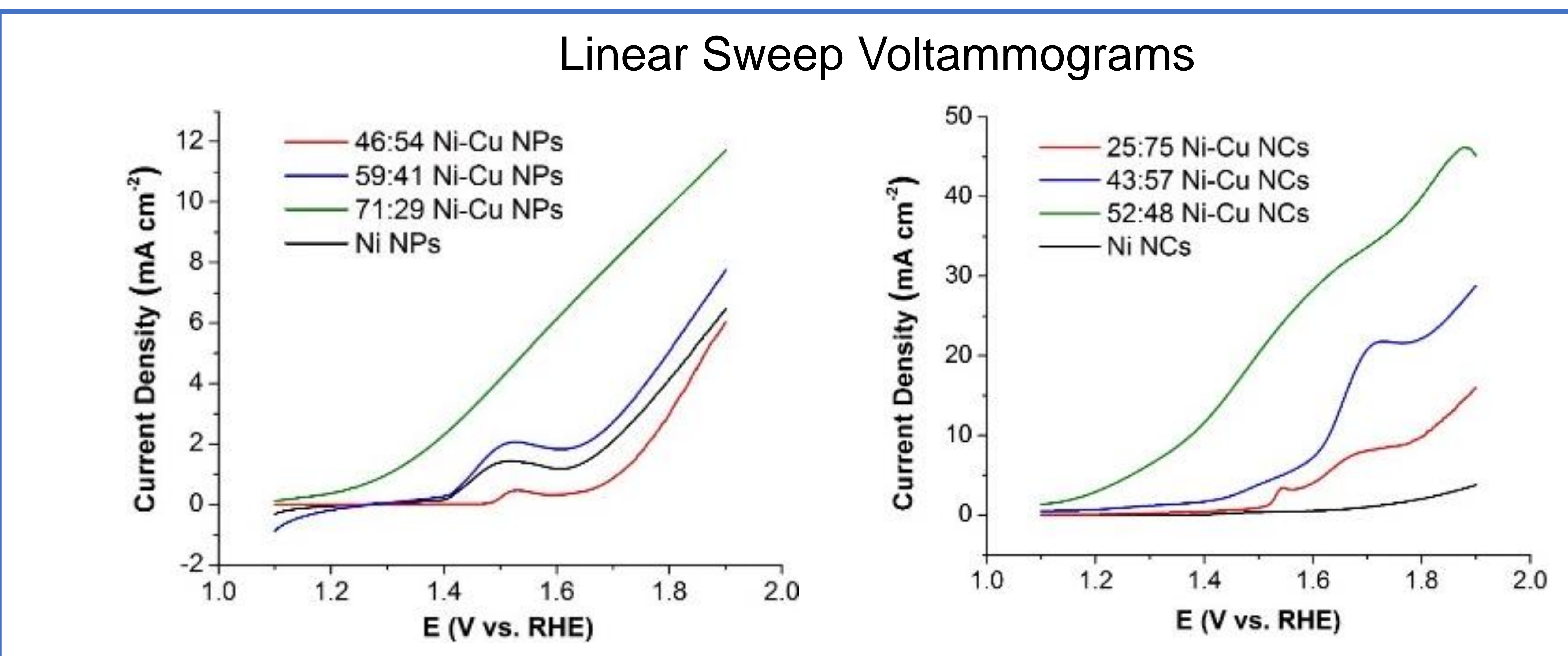

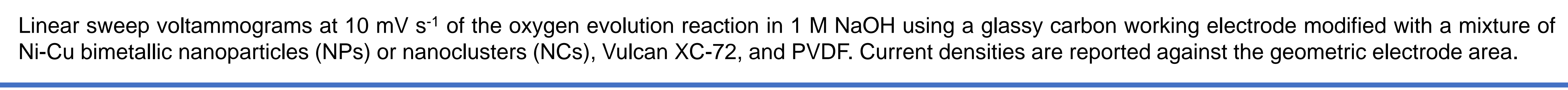

Onset Overpotential and Overpotential for OER

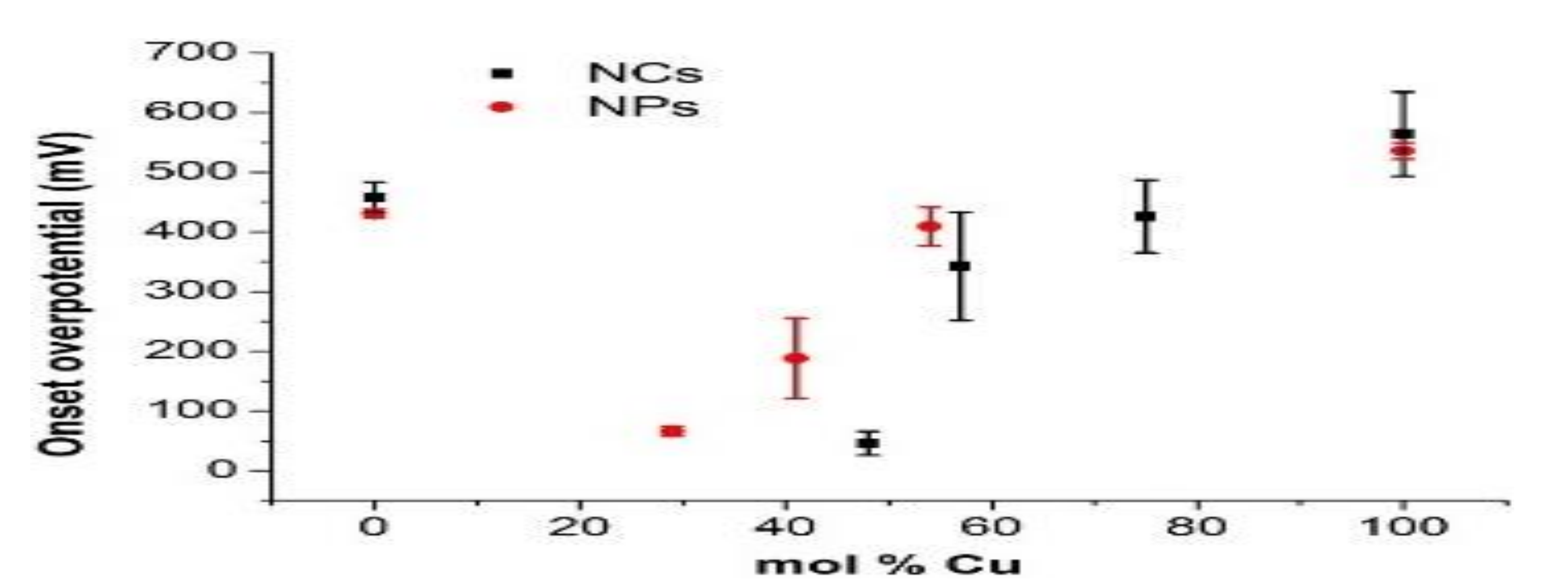

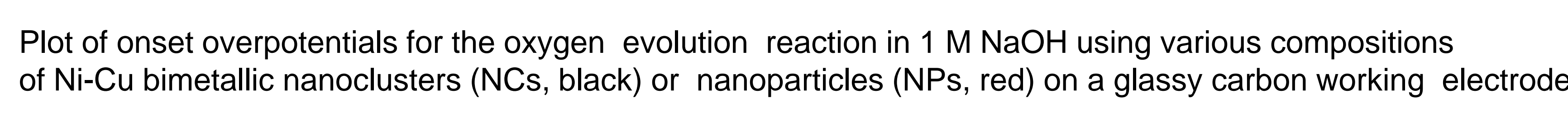

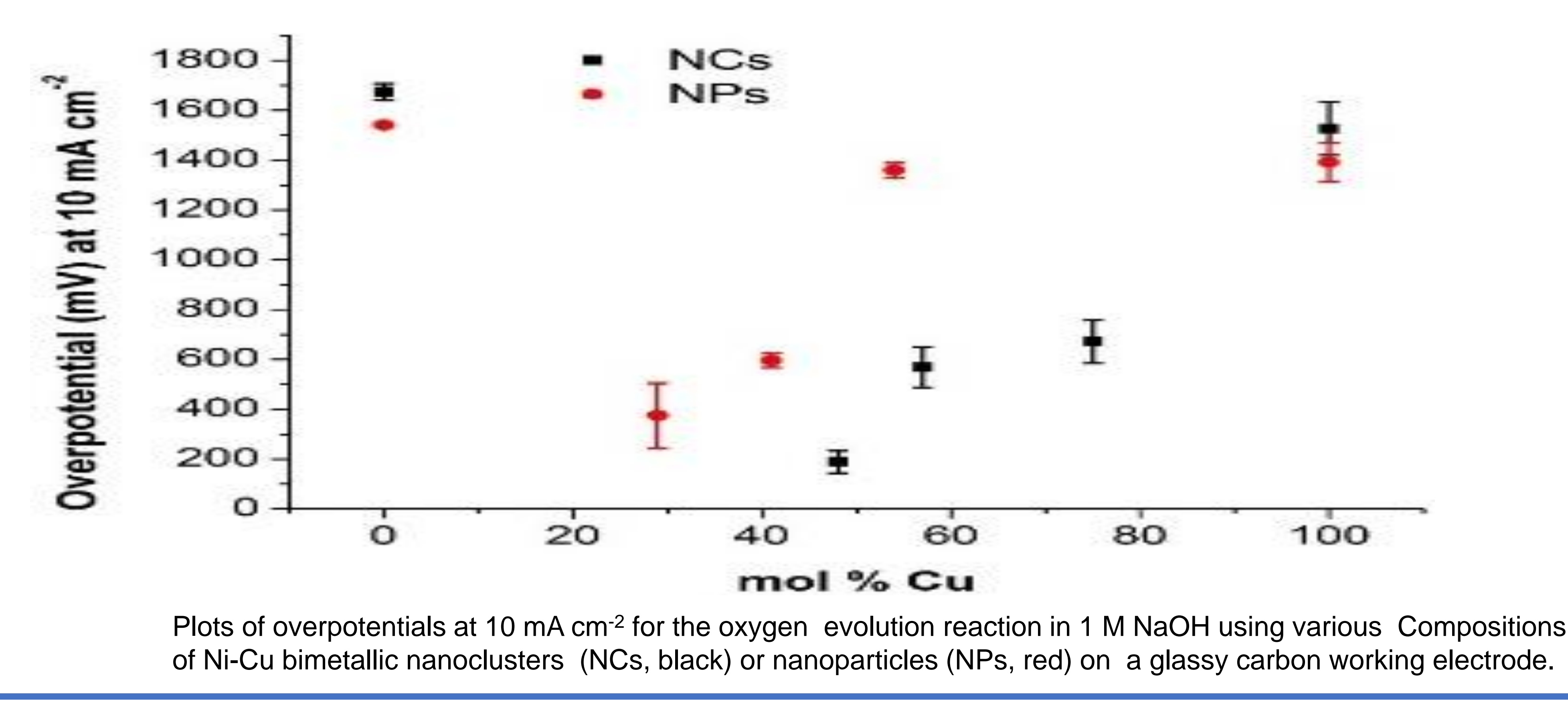

$\mathrm{Pb}$ UPD and ECSA

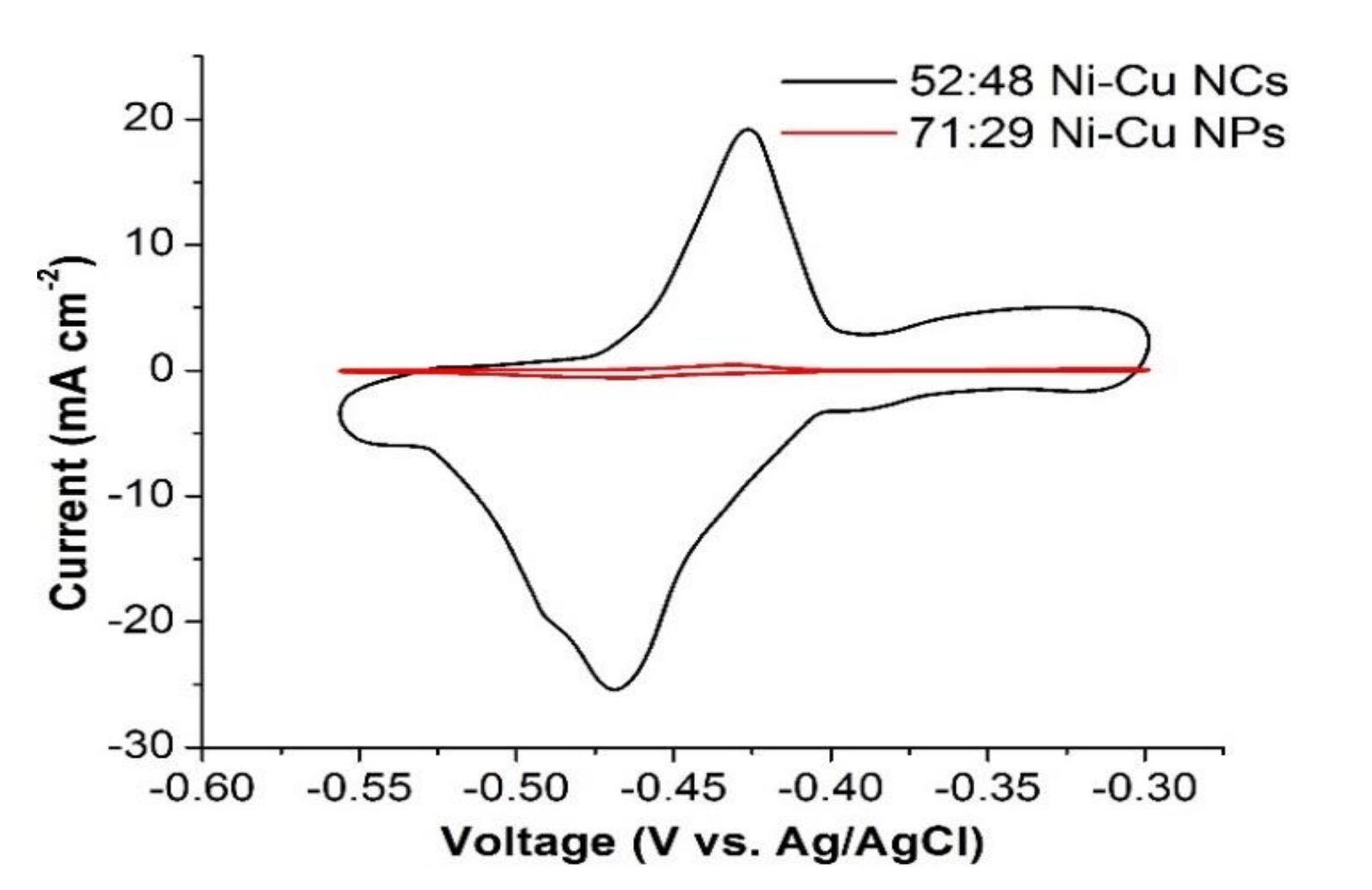

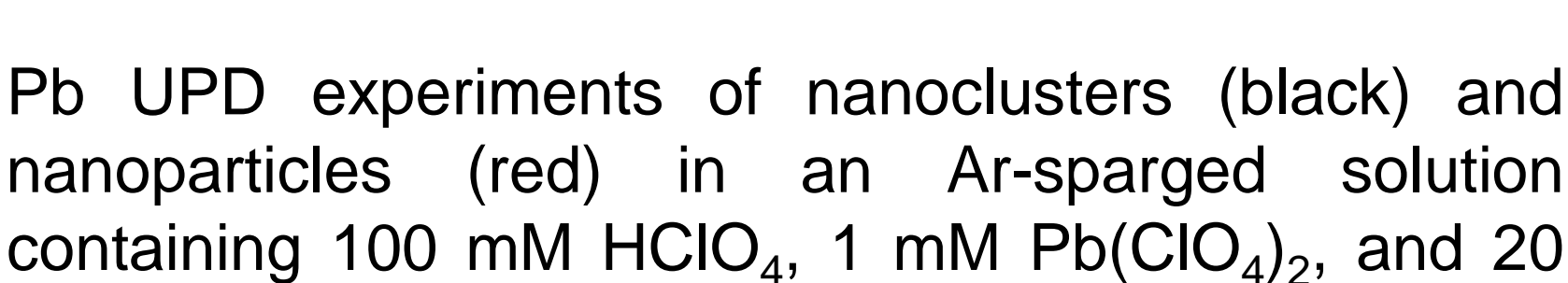

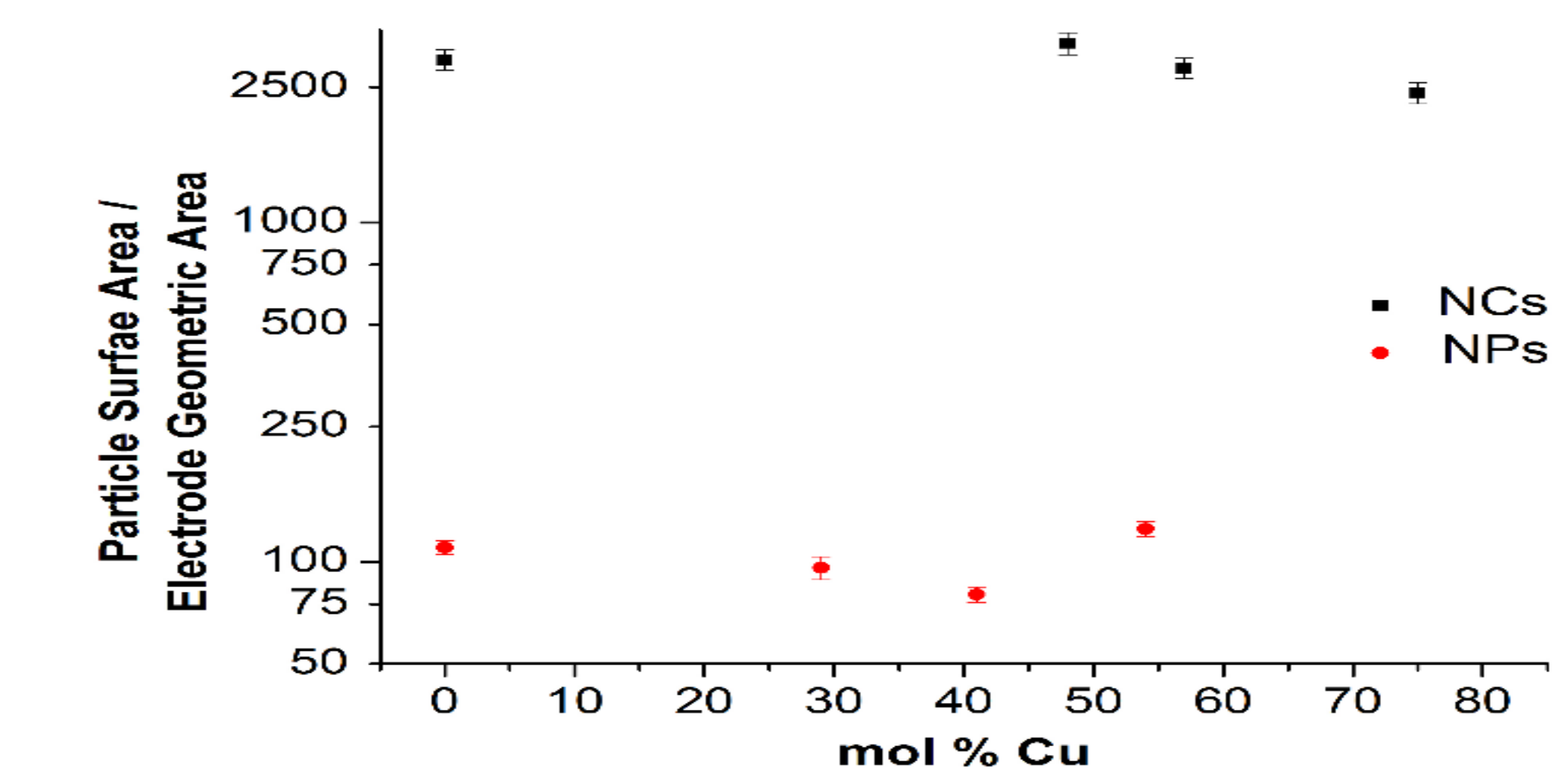

Calculated electrochemically active surface areas of the
nanocolusters (black) and nanoparticles (red) as a

Linear Sweep Voltammograms

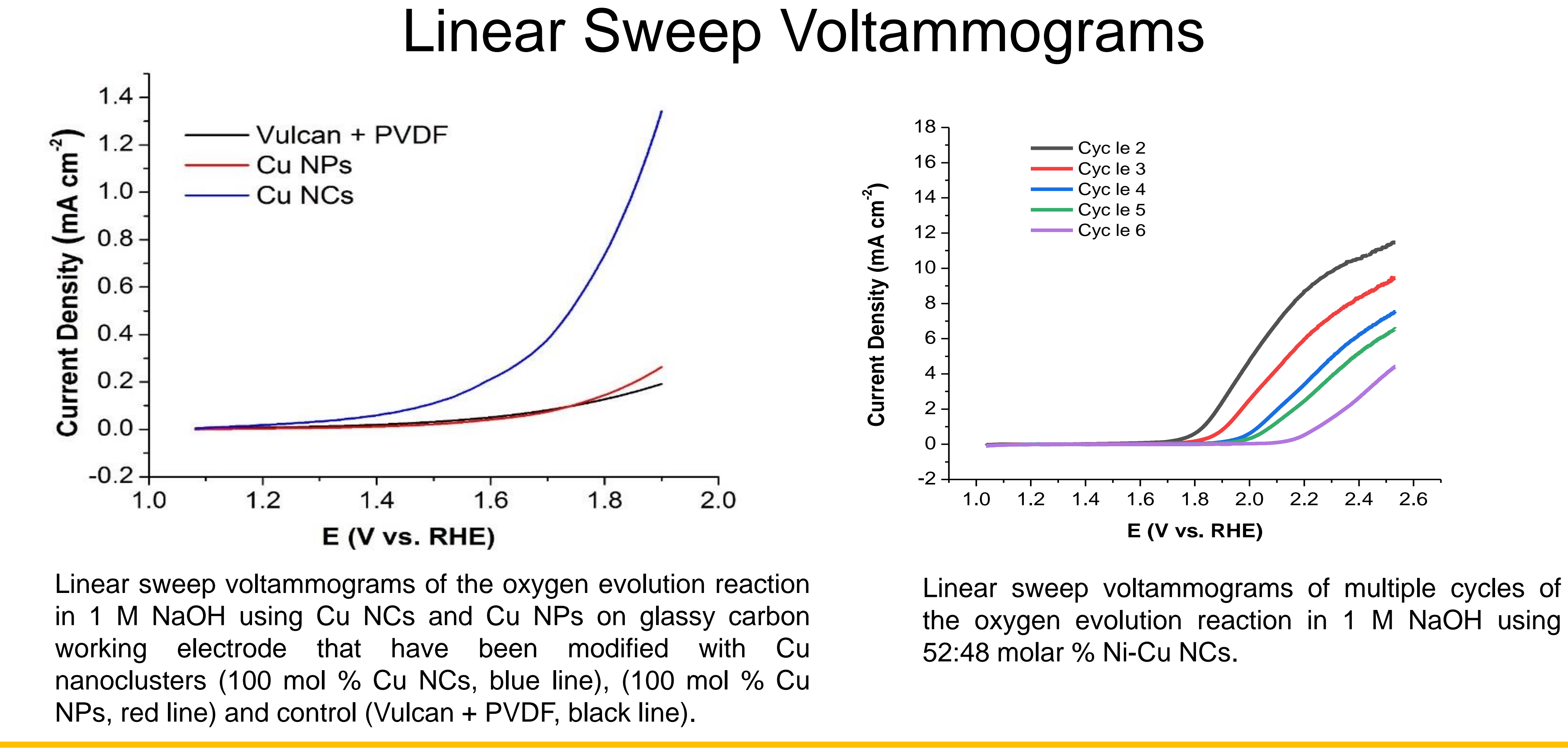

\section{Acknowledgments}

\section{- Research \& Innovation at the University of Nevada, Reno}

Mackay Microbeam Lab at the University of Nevada, Reno (UNR) for SEM-EDX analysis

- National Science Foundation (CHE-1429768) tor the purchase of the powder X-ray diffractiomeder

- The American Chemical Society Petroleum Research fund

National Institutes of Health grant (R15GM1224597)

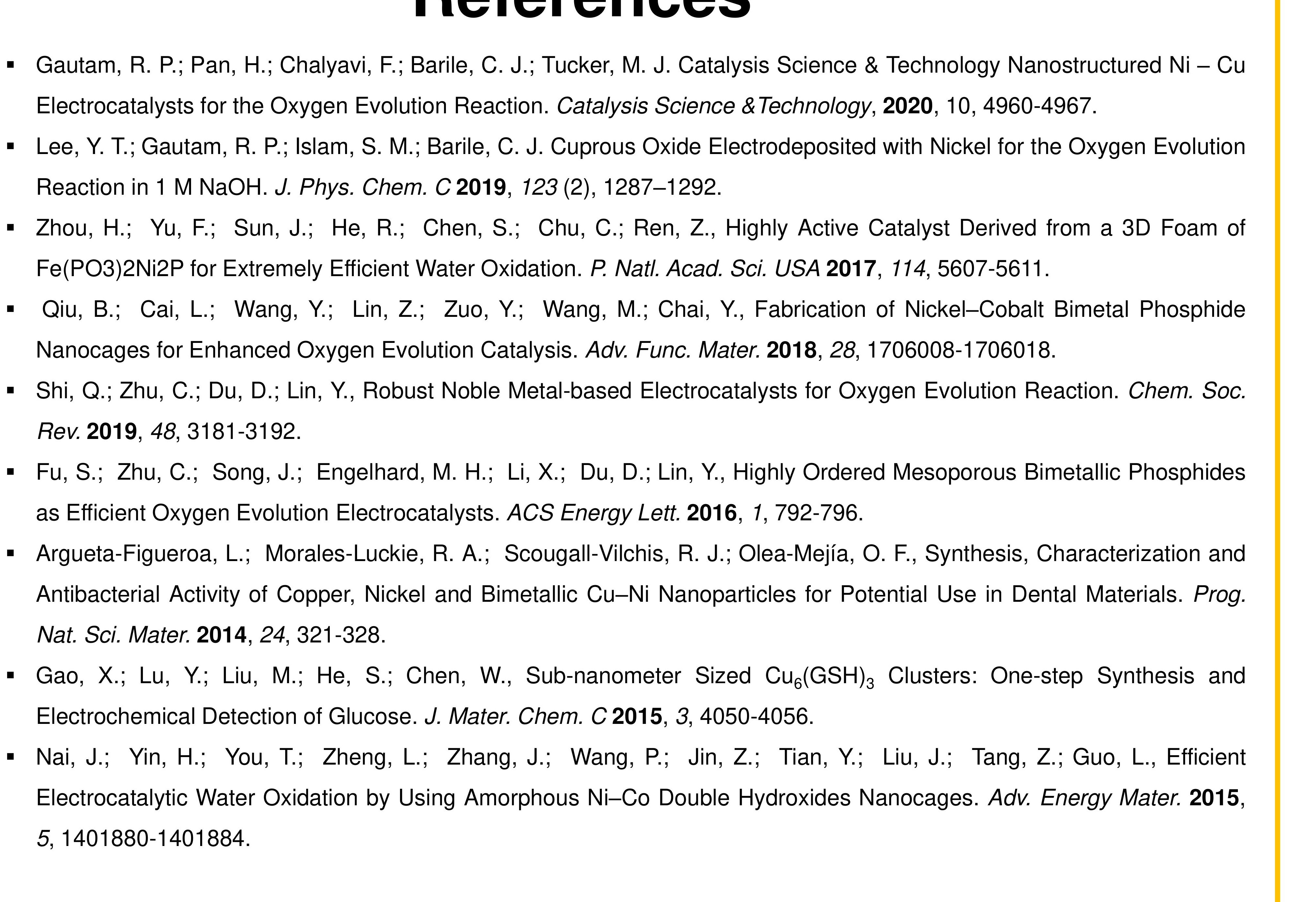

\section{References}

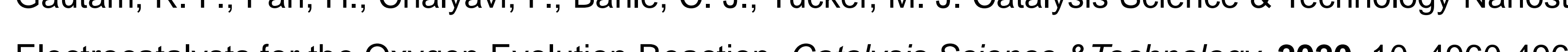
Lee, Y. T.; Gautam, R. P. P. Islam, S. M. Barile, C. . J. Cuprous Oxido

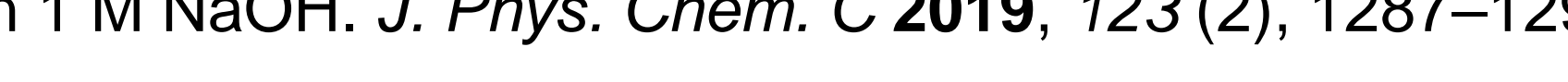

Fe(PO3)2Ni2P tor Extremely Efficient Water Oxidation. P. Natt. Acad. Sci. USA 2017, 114, 5607-56 10.

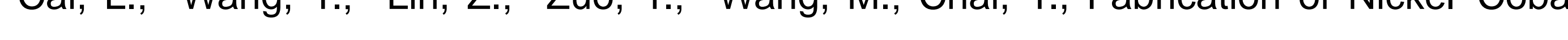

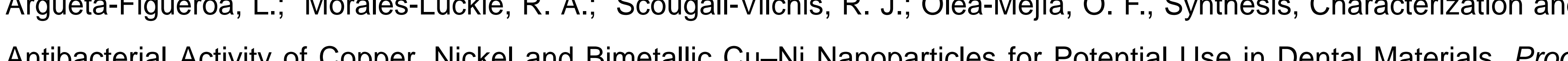

Electrochemical Detection of 